\title{
Polymer Inclusion Membrane (PIM) as Competitive Material for Applications in SPE for Water Treatment Process
}

\author{
Ounissa Senhadji-Kebiche*, Taous Belaid, Mohamed Benamor \\ Laboratory of Membranes Processes, and Techniques of separation and recovery (LPMTSR), Faculty of \\ Technology, Université de Bejaia, Bejaia, Algeria \\ Email: ${ }^{*}$ kebiche_anissa@yahoo.fr, btaous@yahoo.fr, mohamedbenamor@yahoo.fr
}

Received 15 May 2014; revised 20 June 2014; accepted 1 August 2014

Copyright (C) 2014 by authors and OALib.

This work is licensed under the Creative Commons Attribution International License (CC BY).

http://creativecommons.org/licenses/by/4.0/

CC) (i) Open Access

\section{Abstract}

The elaboration of a polymer inclusion membrane (PIM) and solvent impregnated resin (SIR) XAD7 with sorptive characteristics intended for removal of heavy metals was investigated. Bis $(2,4,4-$ trimethylpentyl) monothiophosphinic acid (Cyanex 302) was used as an acidic extractant. The sorption of $\mathrm{Zn}$ (II), $\mathrm{Cu}$ (II) and Fe(II) ions onto the PIM and SIR was investigated and optimized as a function of contact time, $\mathrm{pH}$, extractant amount and concentration of metal ions. Both the PIM and the SIR showed reasonably good ability for the separation of metal ions from ternary mixture. The elution of the metal from the PIM and SIR was accomplished $(100 \%$ and $90 \%$ for PIM and SIR respectively) with $1.0 \mathrm{M} \mathrm{HNO}_{3}$. The elution treatment allows both the polymers to be reused.

\section{Keywords}

Polymer Inclusion Membrane (PIM), Solvent Impregnated Resin (SIR), Heavy Metals Separation, Adsorption

Subject Areas: Analytical Chemistry, Material Experiment

\section{Introduction}

General techniques for metal removal are precipitation, solvent extraction and ion exchange but each process has some limitations in application [1]. Nevertheless, in the last decades new technologies have been proposed. These include techniques which are becoming commercially available or utilized at least to some extent in full or pilot-scale applications, such as membrane separation and electrodialysis, and emerging technologies such as extractive metallurgy and selective adsorption [2].

${ }^{*}$ Corresponding author.

How to cite this paper: Senhadji-Kebiche, O., Belaid, T. and Benamor, M. (2014) Polymer Inclusion Membrane (PIM) as Competitive Material for Applications in SPE for Water Treatment Process. Open Access Library Journal, 1: e758.

http://dx.doi.org/10.4236/oalib.1100758 
Solvent extraction is commonly used for metal recovery from concentrated solutions, but has proved less cost-efficient in the case of dilute solutions. Moreover, in addition to being economical inefficient, there may be a significant environmental impact from the possible loss of extractant during extraction [3].

Immobilizing extractants in suitable solid supports is a solution to prevent these major drawbacks [4] [5]. Impregnated resins have been considered as an alternative process that combines the easy management of solid sorbents and the high efficiency and selectivity of liquid-liquid extraction [6].

The impregnation method is free from difficulties encountered in chemically linking a chelating reagent to a support matrix. In addition, there is a wide choice of reagents for desired selectivity [7].

$\mathrm{XAD}$ resins as the copolymer backbone for the immobilization of chelating ligands have physical superiorities such as porosity, uniform pore size distribution, high surface area, durability, and chemical stability toward acids, bases and oxidizing agents [8]. The most ones frequently used for the preparation of impregnated resins are: divinyl-benzene polymers (Amberlite XAD-2, Amberlite XAD-4) and acrylic polymers (Amberlite XAD-7, Amberlite XAD-8).

In addition to the use of resins, there is considerable interest in using membranes-based systems containing appropriate reagents for solid-phase extraction. There are examples in the literature of successful PVC-based solid-phase extraction systems for the separation of metal ions and small organic molecules [9].

When membranes are incorporated into a transport cell, they allow both extraction and back-extraction to proceed simultaneously at opposite sides of the membrane. This speeds up the separation process compared to conventional adsorption (e.g., ion-exchange resins) or solvent extraction-based separation [10].

In the present work, we propose Polymer Inclusion Membrane (PIM) as competitive material for applications of Solid Phase Extraction (SPE) for water treatment process.

The Polymer inclusion membrane (PIM) and the solvent impregnated resin XAD7 (SIR) with sorptive characteristics were prepared for adsorption of zinc, copper and iron from aqueous nitrate solutions. Bis (2,4,4- trimethylpentyl) monothiophosphinic acid (Cyanex 302) was used as acidic extractant. The potential of organophosphorous extractants viz. Cyanex 272 \{bis (2,4,4-trimethylpentyl) phosphinic acid\} Cyanex 302 \{bis (2,4,4trimethylpentyl) monothiophosphinic acid\} has been well established for d-block as well as for f-block elements [11].

\section{Material and Methods}

\subsection{Reagents}

Bis (2,4,4-trimethylpentyl) monothiophosphinic acid (Cyanex 302) is supplied by Albright and Wilson Co. and used as received. It has a purity of 98.5\%. Cellulose triacetate (CTA), 2-nitrophenyloctylether (2-NPOE) were obtained from Aldrich and were used without further purification. Chloroform ( $\mathrm{CHCl} 3)$ is acquired from Fluka. Amberlite XAD7 resins (Rohm and Hass Co.), size 0.3 - $0.9 \mathrm{~mm}$ and is used as support. The mean pore size is approximate $9 \mathrm{~nm}$ with a surface area of $450 \mathrm{~m}^{2} / \mathrm{g}$ and porosity of $0.55 \mathrm{~cm}^{3} / \mathrm{cm}^{3}$. The density of the resin is 1.25 $\mathrm{mg} / \mathrm{ml}$. Stock zinc, copper and ferrous solutions were prepared by dissolving the corresponding salts in a solution of nitric acid. The total nitrate content was kept constant at $0.1 \mathrm{M}$. The aqueous $\mathrm{pH}$ was changed by adjusting the fractions of $\mathrm{HNO}_{3}$ and $\mathrm{NaOH}$.

All other chemicals used in this work were of analytical reagent grade, and were used without further purification. Double distilled water was used in all experiments.

\subsection{Preparation of Polymeric Membrane and Impregnated Resins}

- The PIM were prepared using a procedure similar to that, reported by Hayashita et al. [12] and already described in our previous works [13] [14]. The membrane thickness was measured by a digital micrometer (Mitutoyo) with $0.1 \mu \mathrm{m}$ standard deviation over 10 readings. The average thickness of the membranes studied is $65 \mu \mathrm{m}$.

- Before impregnation, the resin XAD7 is purified with a 50\% methanol-water solution containing 4M $\mathrm{HCl}$, in order to remove inorganic impurities and monomeric materials. After that, the resin was rinsed thoroughly with doubly distilled water to eliminate chloride ions. For the impregnation, we have followed the dry method [15]. One gram of fresh XAD7 resin is placed in chloroforme containing extractant at different concentrations $(0.01-0.1 \mathrm{~g} / \mathrm{ml})$ for $12 \mathrm{~h}$. Then, the polymeric beads were separated through a porous filter using a vacuum pump, then washed with water and dried at $50^{\circ} \mathrm{C}$. 


\subsection{Procedure}

The solid-phase extraction experiments were conducted in beakers containing $50 \mathrm{ml}$ of the aqueous solution and membrane (cut into segments of approximately equal size) or resin, with an average total mass of $100 \pm 2 \mathrm{mg}$. Then the solution is vigorously shaken for $2 \mathrm{~h}$ to attain equilibrium. After separation of phases, the $\mathrm{pH}$ of the aqueous solution was measured with a digital $\mathrm{pH}$ meter (WTW Inolab pH).

The concentration of the metal in the solution at various contact time intervals, in the experiments of extraction and back extraction is monitored by taking $0.2 \mathrm{ml}$ samples for analysis.

The concentration of metal ions is evaluated using a Shimadzu atomic absorption spectrophotometer (model AA 6501f) with air-acetylene flame. The quantities of adsorbed ionic metal and the unreacted DEHPA in the SIR were calculated from a mass balance. Each experiment is duplicated under the same conditions (the error is general within $5 \%$ ).

The distribution ratio of the metal ion is obtained using the following equation:

$$
D=\frac{V}{m} \cdot \frac{C_{0}-C}{C}
$$

where $V$ is the volume of the aqueous phase $(\mathrm{mL}), m$ stands for the mass of dry membrane or resin (g), $C_{0}$ and $C$ denote the initial total concentration and the equilibrium concentration of metal ions in aqueous phase respectively.

\section{Results and Discussion}

\subsection{Evaluation of the Impregnation Concentration Effect}

To study the effect of the initial concentration of the extractant, several samples $0.5 \mathrm{~g}$ mass of the resin have been in contact (for 24 hours) with $10 \mathrm{ml}$ of chloroform $(\mathrm{CH} 3 \mathrm{Cl}$ ) containing amount ranging from $0.0723 \mathrm{~g}$ to $0.2825 \mathrm{~g}$ of bis(2,4,4-trimethylpentyl)monothiophosphinic acid (Cyanex 302). Figure 1 show that the extractant content vary linearly with the extractant concentration in the solution. This suggests that there is no saturation plateau. Similar observations were reported by Saha et al. [16] and Kabay et al. [17] for impregnation of Amberlite XAD-7 resin with Aliquat 336 and Diaion HP-20 and HP-2 MG with Aliquat 336 respectively. In addition, the authors observed a plateau at an impregnation ratio of 2.5 (g Aliquat 336/g polymer) for HP-2MG.

It should be noted impregnation ratios above 0.565 g Cyanex 302/g Amberlite XAD-7 were not investigated in the present work, because of the possible leaching of the Cyanex 302 from the SIR (at higher impregnation ratio) and it is highly unlikely there is not a saturation plateau at higher impregnation ratio.

\subsection{Influence of Contact Time}

The time-dependent extraction of Zn(II) with the Cyanex 302/polymer inclusion membrane and the impregnated resin, is studied at constant values of $\mathrm{pH}$, concentration of $\mathrm{M}$ (II) and mass of solids (SIR and PIM) $(\mathrm{pH}=3$, $[\mathrm{Zn}(\mathrm{II})]=10 \mathrm{ppm}$ and $\mathrm{mS}=100 \mathrm{mg}$ ). The contact time is varied from 0 to $280 \mathrm{~min}$ and curves shown in Figure 2 indicate a fast adsorption of the ionic metal on the solid sorbents. As can be seen, the equilibrium is reached at about 120 minutes. Therefore, $120 \mathrm{~min}$ is adopted as the optimal extraction time for subsequent studies to ensure complete equilibration.

\subsection{Effect of the $\mathrm{pH}$}

The results of effect of the $\mathrm{pH}$ on the extraction of $\mathrm{Zn}(\mathrm{II})$ from its solution by SIR and PIM are given in Figure 3. We can note down that the extraction of the metal ions increases with increasing $\mathrm{pH}$. The effectiveness extraction of Zn(II) by PIM reached about $91 \%$ at $\mathrm{pH} 4.8$ while it was about $48 \%$ when the SIR is used for the extraction. From $\mathrm{pH} 4.8$, the effectiveness extraction tends to have a constant value for both materials. We can conclude that the interval $\mathrm{pH}$ of 4.8 to 6.0 is favorable for a best extraction.

Bari et al. [1] have also found that the extraction of the metal ions ( $\mathrm{Zn}(\mathrm{II}), \mathrm{Cu}(\mathrm{II})$ and $\mathrm{Ni}(\mathrm{II})$ ) by sol-gel silica containing Cyanex 272 (SGSIC) increases with increasing $\mathrm{pH}$. The extraction of $\mathrm{Zn}$ (II) reached about $95 \%$ at $\mathrm{pH} 3.0$ while the extraction of $\mathrm{Cu}(\mathrm{II})$ and $\mathrm{Ni}(\mathrm{II})$ were about $13 \%$ and $2 \%$, respectively. The extraction of $\mathrm{Cu}(\mathrm{II})$ reached around $72 \%$ at $\mathrm{pH} 4.2$, whereas the extraction of $\mathrm{Ni}(\mathrm{II})$ at this $\mathrm{pH}$ was only $7 \%$. However, extraction of $\mathrm{Ni}(\mathrm{II})$ was $91 \%$ at $\mathrm{pH} 6.2$. 


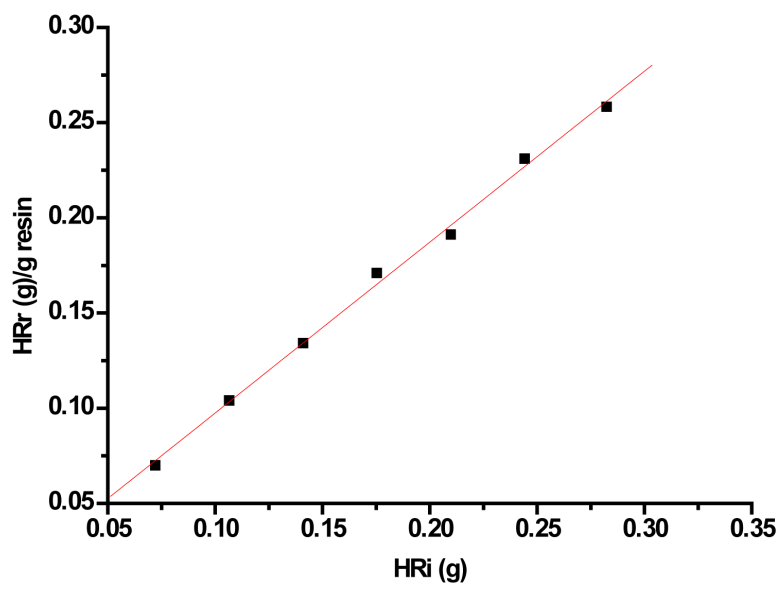

Figure 1. Evolution of the Amberlite XAD-7 impregnation in function of Cyanex 302 concentration in resin.

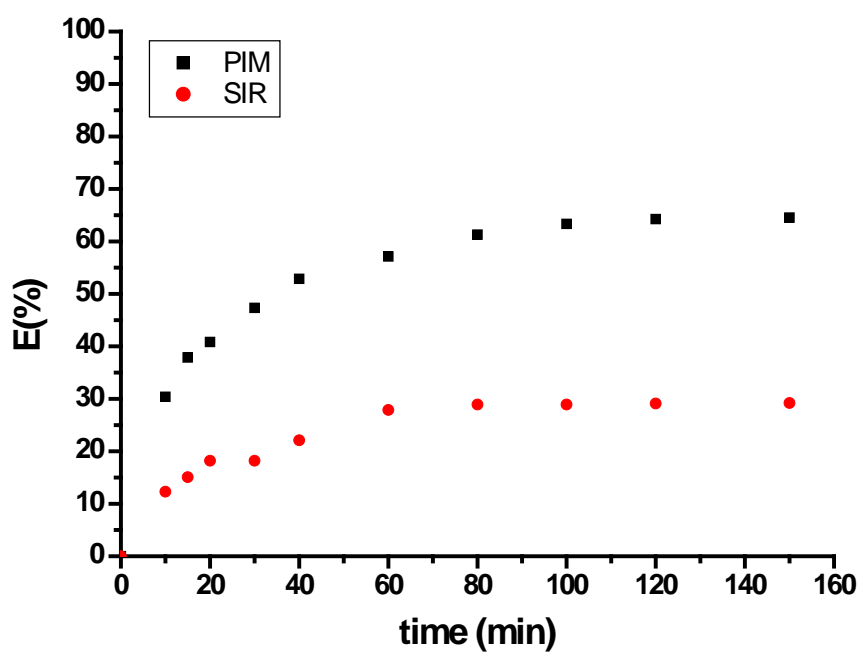

Figure 2. Effect of contact time on the extraction of $\mathrm{Zn}^{2+}$ with (a) SIR ([Cyanex 302] = $1 \mathrm{~mol} / \mathrm{kg}$ SIR); (b) PIM ([Cyanex 302] = 10 $\left.\mu \mathrm{mol} / \mathrm{cm}^{2}\right),\left[\mathrm{Zn}^{2+}\right]=10 \mathrm{mg} / \mathrm{L}, \mathrm{pH}_{\mathrm{i}}=3.04$.

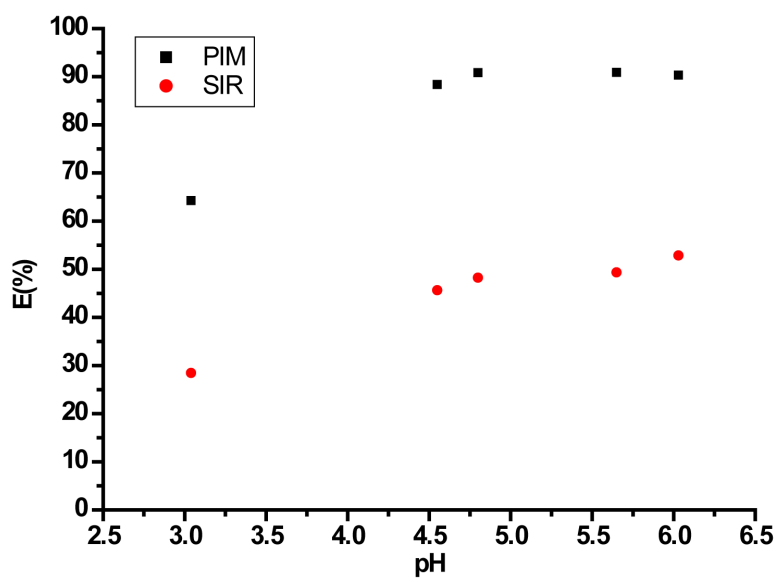

Figure 3. $\mathrm{pH}$ effect on the adsorption of $\mathrm{Zn}^{2+}$ onto (a) SIR ([Cyanex 302] = $1 \mathrm{~mol} / \mathrm{kg}$ SIR); (b) PIM ([Cyanex 302] = 10 $\left.\mu \mathrm{mol} / \mathrm{cm}^{2}\right),\left[\mathrm{Zn}^{2+}\right]=10 \mathrm{mg} / \mathrm{L}$. 


\subsection{Effect of Initial Zn(II) Concentration}

The effect of the initial concentration of Zn(II) on the effectiveness of the extraction process is shown in Figure 4. It can be seen that for lower initial concentration of the metal $(10 \mathrm{mg} / \mathrm{L})$ highest efficiency is obtained. However, this is not the case for higher initial concentrations $(20,30$ and $40 \mathrm{mg} / \mathrm{L})$, this is probably due to the insufficient quantity of Cyanex 302 in the two solid adsorbents (SIR and PIM) studied.

The comparison of retention properties of resin and membrane shows that complexing capacities of Zn (II) appear to be higher for the membrane (PIM): this outcome could be related to the greater availability of the sites of complexation in the polymer membrane compared with the impregnated resin.

\subsection{Solid/Liquid Extraction of Cu(II), Zn(II) and Fe(II)}

The extraction experiments were conducted in duplicate. Each experiment involved the immersion of the adsorbent (SIR or PIM) with an average mass of $100 \mathrm{mg}$ into a $50 \mathrm{~mL}$ aqueous solution containing $\mathrm{Zn}$ (II), $\mathrm{Cu}$ (II) or $\mathrm{Fe}(\mathrm{II})$.

The stirring rate was maintained at $350 \mathrm{rpm}$ and the $\mathrm{pH}$ fixed at the optimal value 6 .

Figure 5(a) \& Figure 5(b) show that both the PIM and the SIR provide a reasonably good ability for the separation of metal ions from ternary mixture.

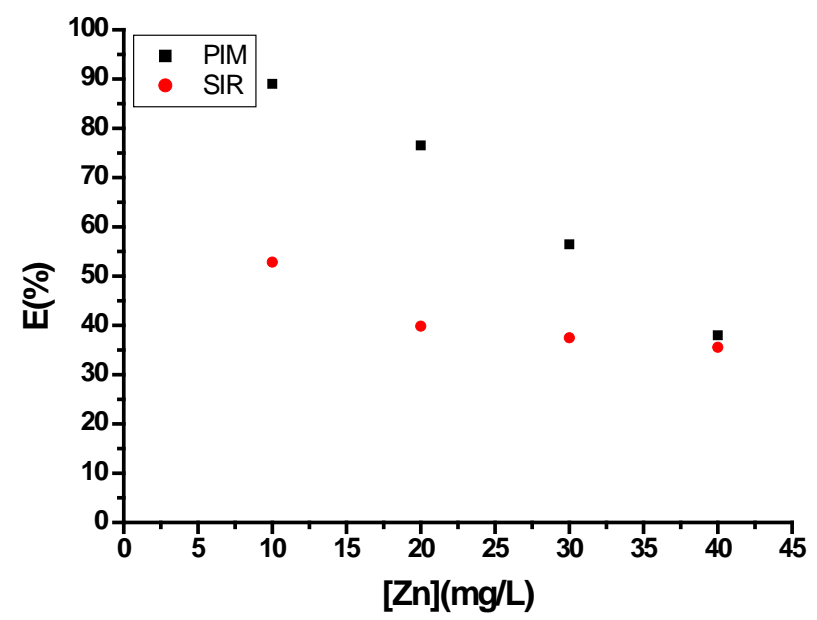

Figure 4. Concentration dependence of the $\mathrm{Zn}^{2+}$ ions uptake from aqueous solutions by (a) SIR ([Cyanex 302] = $1 \mathrm{~mol} / \mathrm{kg}$ SIR); (b) PIM ([Cyanex 302] = $10 \mu \mathrm{mol} / \mathrm{cm}^{2}$ ).

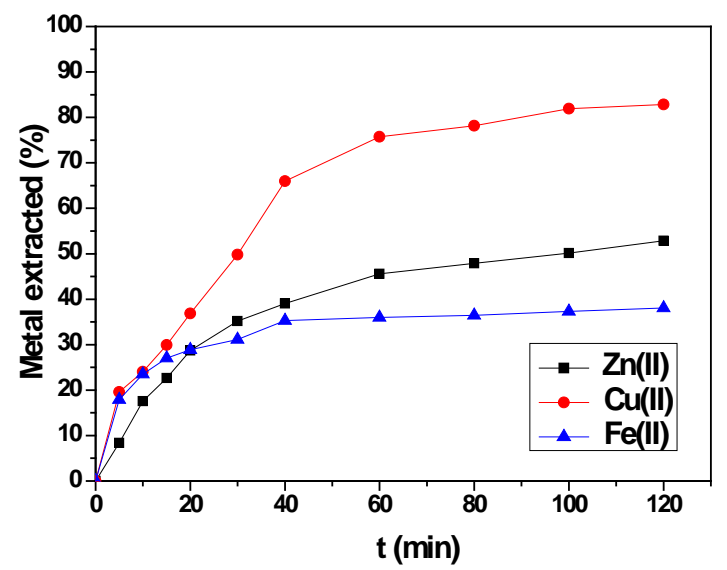

(a)

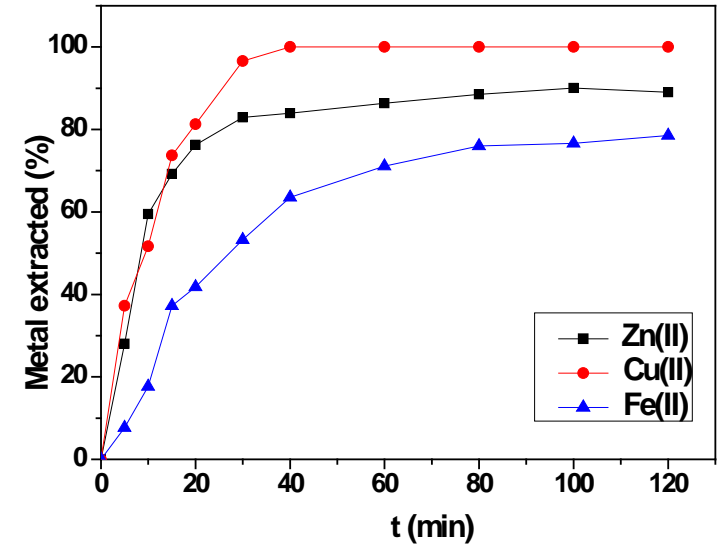

(b)

Figure 5. Percentage of extraction vs time for the three metal ions $\mathrm{Cu}$ (II), $\mathrm{Zn}$ (II), and Fe (II) uptake from aqueous solutions by (a) SIR ([Cyanex 302] = $1 \mathrm{~mol} / \mathrm{kg}$ SIR); (b) PIM ([Cyanex 302] $=10 \mu \mathrm{mol} / \mathrm{cm}^{2}$ ). 
So, when the SIR is used as adsorbent, the percentage of extraction reaches $82.86 \%, 52.84 \%, 38.05 \%$ for the three metal ions $\mathrm{Cu}$ (II), Zn (II), and Fe (II) respectively. However, when the PIM is used as adsorbent, the extraction efficiency is in the order of $100 \%, 89.02 \%$, and $78.56 \%$ for $\mathrm{Cu}$ (II), $\mathrm{Zn}$ (II) and Fe (II) respectively.

It can be concluded that the Amberlite XAD 7 Cyanex 302-impregnated resin has a high affinity towards the $\mathrm{Cu}$ (II) compared with Zn (II) and Fe (II) and that the PIM has more high affinity towards $\mathrm{Cu}$ (II) and Zn (II). This may be related to the ionic radius of each of the three ions, and the facilitated access to the active sites (the extractant) of the adsorbent (PIM or SIR).

\subsection{Regeneration of the Solid Adsorbents}

To become economically competitive, the adsorbent should have the capability of reuse. Desorption of the metal makes possible the reuse of the adsorbent and recycling the metal. Selective desorption may also be helpful for the separation of metal ions in the case of metal recovery from multi-component solutions.

In this study $0.2 \mathrm{~g}$ of the adsorbent (containing the $\mathrm{Zn}$ (II) after extraction) is put in $100 \mathrm{~mL}$ aqueous solution of $1 \mathrm{M} \mathrm{HNO}_{3}$. The mixture is mechanically shaken for $120 \mathrm{~min}$ at room temperature. After filtration, the concentration of the metal in the acidic aqueous solution is determined to evaluate the elution effectiveness. The obtained results show that the eluent $\left(\mathrm{HNO}_{3}\right)$ recovered the loaded zinc with efficiencies near $90 \%$ and $100 \%$ for SIR and PIM, respectively.

This can be explained by a proton-metal exchange mechanism $\left(\mathrm{Zn}^{2+} \leftrightarrow \mathrm{H}^{+}\right)$in the both adsorbents.

\section{Conclusions}

On the base of the established results it can be concluded that Cyanex 302/solid adsorbent membranes (PIM) provide an attractive alternative to conventional solvent extraction methods for the removal of $\mathrm{Zn}(\mathrm{II}), \mathrm{Cu}(\mathrm{II})$ and $\mathrm{Fe}(\mathrm{II})$. The back extraction of $\mathrm{Zn}(\mathrm{II})$ into $1 \mathrm{M} \mathrm{HNO}_{3}$ was found to be fast and quantitative.

All results of the extraction and the back-extraction indicate that using membranes is more efficient than resin, for the extraction of metal ions studied here, with additional advantage of use of a lower amount of the extractant.

The present study allows considering polymer inclusion membranes as competitive materials for SPE applications, and even for water treatment applications.

Further studies regarding the possibilities of separating Zn(II) from aqueous solution in the presence of a wide range of metal ions must be explored. In addition, other experiments with the PIM incorporated into a transport cell (which allows both extraction and back-extraction to proceed simultaneously at opposite sides of the membrane) must complete the work in future.

\section{References}

[1] Bari, F., Begum, N., Jamaludin, S.B. and Hussin, K. (2009) Extraction and Separation of Cu(II), Ni(II) and Zn(II) by Sol-Gel Silica Immobilized with Cyanex 272. Hydrometallurgy, 96, 140-147.

http://dx.doi.org/10.1016/j.hydromet.2008.09.006

[2] Cortina, J.L., Miralles, N., Aguilar, M. and Sastre, A.M. (1994) Solvent Impregnated Resins Containing Di(2-EthylHexyl)Phosphoric Acid.II. Study of the Distribution Equilibria of Zn(II), Cu(II) and Cd(II). Solvent Extraction and Ion Exchange, 12, 371-391. http://dx.doi.org/10.1080/07366299408918215

[3] Navarro, R., Saucedo, I., Nunez, A., Avila, M. and Guiba, E. (2008) Cadmium Extraction from Hydrochloric Acid Solutions Using Amberlite XAD-7 Impregnated with Cyanex 921 (Tri-Octyl Phosphine Oxide). Reactive \& Functional Polymers, 68, 557-571. http://dx.doi.org/10.1016/j.reactfunctpolym.2007.10.027

[4] Navarro, R., Saucedo, I., Avila, M., Gonzalez, M.P. and Garcia, S. (2007) Zinc(II) Extraction from Hydrochloric Acid Solutions using Amberlite XAD-7 Impregnated with Cyanex 921 (Tri-Octyl Phosphine Oxide). Solvent Extraction and Ion Exchange, 25, 273-297. http://dx.doi.org/10.1080/07366290601169386

[5] Gallardo, V., Navarro, R., Saucedo, I., Avila, M. and Guibal, E. (2008) Zinc(II) Extraction from Hydrochloric Acid Solutions Using Amberlite XAD-7 Impregnated with Cyphos IL 101 (Tetradecyl(Trihexyl)Phosphonium Chloride). Separation Science and Technology, 43, 2434-2459. http://dx.doi.org/10.1080/01496390802119002

[6] Arias, A., Saucedo, I., Navarro, R., Gallardo, V., Martinez, M. and Guibal, E. (2011) Cadmium(II) Recovery from Hydrochloric Acid Solutions Using Amberlite XAD-7 Impregnated with a Tetraalkyl Phosphonium Ionic Liquid. Reactive \& Functional Polymers, 71, 1059-1070. http://dx.doi.org/10.1016/j.reactfunctpolym.2011.07.008 
[7] Hosseini, M.S., Hosseini-Bandegharaei, A., Raissi, H. and Belador, F. (2009) Sorption of Cr(VI) by Amberlite XAD-7 Resin Impregnated with Brilliant Green and Its Determination by Quercetin as a Selective Spectrophotometric Reagent. Journal of Hazardous Materials, 169, 52-59. http://dx.doi.org/10.1016/j.jhazmat.2009.03.058

[8] Çekiç, S.D., Filik, H. and Apak, R. (2004) Use of an o-Aminobenzoic Acid-Functionalized XAD-4 Copolymer Resin for the Separation and Preconcentration of Heavy Metal(II) Ions. Analytica Chimica Acta, 505, 15-24. http://dx.doi.org/10.1016/S0003-2670(03)00211-3

[9] Nghiem, L.D., Mornane, P., Potter, I.D., Perera, J.M., Cattrall, R.W. and Kolev, S.D. (2006) Extraction and Transport of Metal Ions and Small Organic Compounds Using Polymer Inclusion Membranes (PIMs). Journal of Membrane Science, 281, 7-41. http://dx.doi.org/10.1016/j.memsci.2006.03.035

[10] Kolev, S.D., Baba, Y., Cattrall, R.W., Tasaki, T., Pereira, N., Perera, J.M. and Stevens, G.W. (2009) Solid Phase Extraction of Zinc(II) Using a PVC-Based Polymer Inclusion Membrane with Di(2-ethylhexyl)phosphoric Acid (D2EHPA) as the Carrier. Talanta, 78, 795-799. http://dx.doi.org/10.1016/j.talanta.2008.12.047

[11] Karve, M. and Rajgor, R.V. (2008) Amberlite XAD-2 Impregnated Organophosphinic Acid Extractant for Separation of Uranium(VI) from Rare Earth Elements. Desalination, 232, 191-197. http://dx.doi.org/10.1016/j.desal.2007.12.016

[12] Hayashita, T., Kumazawa, M., Lee, J.C. and Bartsch, R.A. (1995) Sodium Ion Sensing by Cellulose Triacetate Plasticizer Membrane Containing Dibenzo-16-Crown-5 Chromoionophore. Chemistry Letters, 24, 711-712. http://dx.doi.org/10.1246/cl.1995.711

[13] Kebiche-Senhadji, O., Mansouri, L., Tingry, S., Seta, P. and Benamor, M. (2008) Facilitated Cd(II) Transport across CTA Polymer Inclusion Membrane Using Anion (Aliquat 336) and Cation (D2EHPA) Metal Carriers. Journal of Membrane Science, 310, 438-445. http://dx.doi.org/10.1016/j.memsci.2007.11.015

[14] Kebiche-Senhadji, O., Tingry, S., Seta, P. and Benamor, M. (2010) Selective Extraction of Cr(VI) over Metallic Species by Polymer Inclusion Membrane (PIM) Using Anion (Aliquat 336) as Carrier. Desalination, 258, 59-65. http://dx.doi.org/10.1016/j.desal.2010.03.047

[15] Benamor, M., Bouariche, Z., Belaid, T. and Draa, M.T. (2008) Kinetic Studies on Cadmium Ions by Amberlite XAD7 Impregnated Resins Containing Di(2-ethylhexyl) Phosphoric Acid as Extractant. Separation and Purification Technology, 59, 74-84. http://dx.doi.org/10.1016/j.seppur.2007.05.031

[16] Saha, B., Gill, R.J., Bailey, D.G., Kabay, N. and Arda, M. (2004) Sorption of Cr(VI) from Aqueous Solution by Amberlite XAD-7 Resin Impregnated with Aliquat 336. Reactive \& Functional Polymers, 60, 223-244. http://dx.doi.org/10.1016/j.reactfunctpolym.2004.03.003

[17] Kabay, N., Arda, M., Saha, B. and Streat, M. (2003) Removal of Cr(VI) by Solvent Impregnated Resins (SIR) Containing Aliquat 336. Reactive \& Functional Polymers, 54, 103-115. http://dx.doi.org/10.1016/S1381-5148(02)00186-4 